\title{
The Practical Problems and the Solution of Aesthetic Education Under the Context of Value Pluralism
}

\author{
Lulu Sun ${ }^{1,2, *}$, Xing $\mathrm{Li}^{3}$ \\ ${ }^{1}$ School of Humanities, Huazhong University of Science and Technology, Wuhan 430074, China \\ ${ }^{2}$ School of Art and Literature, Shihezi University, Shihezi 832000, China \\ ${ }^{3}$ School of Education Science and Technology, Jinzhong University, Jinzhong 030619, China \\ ${ }^{*}$ Corresponding author. Email: 124658782@qq.com
}

\begin{abstract}
Under the context of value pluralism, aesthetic education in the colleges encounters both internal and external crises which are characterized by the fact that aesthetic education is shifting from the academic domain to practicality, namely, from the western enlightenment concept under the context of west philosophical aesthetics to the systematic practice acting on the national lives. The common predicaments are reflected by the poor adjustment to the reform of aesthetic education, the dispersion and fragmentization of the curriculum system, and the confinement of aesthetic capacity into professional cognitive practice. This paper attempts to explore the function of teachers have in leading to those predicaments, thus, to overcome the bottleneck in the policy-making for aesthetic education, to break the barrier limiting the professional developmental, and to conquer the contradiction between the substantiation and the nonsubstantiation. This paper puts forward that enforcing the aesthetic education should start with remodelling the philosophy of "mega aesthetic education" from the origin, while establishing teaching and researching base for aesthetic courses in universities, and promoting the digitalization of aesthetic course teaching.
\end{abstract}

Keywords: Value pluralism, Aesthetic education in higher education, Practical reform.

\section{INTRODUCTION}

The concept of "aesthetic education" is originated from On the Aesthetic Education of Man by German scholar Freidrich Schiller. In the beginning of the 20th century, Guowei Wang translated it into Chinese, and Yuanpei Cai went further by elaborating it in the national education objectives.(Tang,Yingjie 2002) In China, aesthetic education has been so highly valued that recently the Ministry of Education carries out the "Action Plan for Aesthetic Education Infiltration". However, the aesthetic education faces both the internal and external crises. At present, people's value, discourse concepts, and the lifestyles become much more diversified and divergent, which are influenced by the new communication methods with typical contemporary characteristics. Under this context, aesthetic education in higher education faces the enormous challenges: for one thing, it undertakes the responsibilities of fostering students' humanistic quality, expanding students' horizons, and cultivating students' taste; for another, it has to confront the conflict of value pluralism. In the new era, how to promote aesthetic education in higher education, enhance the quality of aesthetic curriculum teaching and carry out the aesthetic infiltration are of great significance to enforcing the ideology in the curricula and promoting socialist core values.

\section{THE PROBLEMS OF AESTHETIC EDUCATION IN HIGHER EDUCATION UNDER THE CONTEXT OF VALUE PLURALISM}

The aesthetic education spans from the academic field to the practical field, which brings about subtle changes to its connotation. The aesthetic practice is an enlightening concept under the western philosophical and aesthetic context, which gradually becomes a kind of systematic practice acting on the national lives. The most obvious carrier of this practice is to design a set of aesthetic education curricula. In terms of the aesthetic education in China, it contains not merely compulsory courses, selective courses, and aesthetic professional courses, but also club activities and campus cultural edification, etc. The purpose of the curricula is to expose students to the basic aesthetic knowledge, to 
cultivate aesthetic taste, acquire the appreciative capacity, and thus to help them build up desirable personality traits and value system. However, in practice, a few problems emerge

\subsection{The Insufficient Adjustment to the Reform of Aesthetic Education}

With the rise of the new-media tools, the information transmission is reshapeing people's thoughts, concepts, and values system unconsciously. The traditional relationship between teachers and students is challenged. Teachers are no longer the "knowledge container"; students are not satisfied with single-direction knowledge transmission any more. Today's college students are born in the information age. The new means of gaining information brings about the fragmentization, deauthority and autonomy of information channels. At the same time, teachers cannot adapt themselves to the methods of new aesthetic transmission. Some teachers still rely heavily on those existing textbooks to transmit aesthetic knowledge, neglecting students' daily lives and the social issues. The aesthetic education has been an "island" far away from college students. Facing the age of new-media, universities per se still held the traditional understanding about the aesthetic education and fail to be aware of its significance in reshaping students' psychological health and perfecting students' personality. In one word, aesthetic education does not accord with moral, intellectual, physical, and labouring education.

\subsection{The Dispersion and Fragmentization of the Curriculum System}

A lot of universities do not have specific aesthetic courses, and college students mistake the courses, "the fine arts", "the aesthetic course", "the appreciating course", "the literary review" as the aesthetic education. In fact, these courses, however, are merely a part of aesthetic education. What's more, the situation of the aesthetic education curricula in higher education is far from being satisfactory. The curricula only contain music, calligraphy, film and television art, college Chinese course, and the reciting appreciation, etc., which mostly are selective courses and lack of the beauty in modern times. At present, the task, design, organizing, teaching device service, and expenditure investment of the aesthetic education in higher education are still weak and feeble, and it is not taken as an independent course. What's worse, there are no professional aesthetic faculty and specific textbooks in this field, and the direction of the aesthetic education is vague and its teaching content is not abundant and profound.

\subsection{The Aesthetic Competence Confined to the Professional Cognitive Practice}

The aesthetic education is different from the aesthetics. The aesthetic major is devoted to learn the systematic aesthetic courses and specific aesthetic skills, and to cultivate talents equipped with aesthetic theory and practice; however, the aesthetic education ultimately is a value education regarding to people's materialistic life and spiritual world. In reality, the aesthetic education is usually endowed with the professional aesthetic cognition. On the one hand, the curricula of the aesthetic education and the aesthetic course are almost the same. Some colleges arrange their aesthetic education curricula grounded on the aesthetic courses, and some even offer the general course "Appreciation to the Aesthetic Works". However, those professors neglect the distinctions between the aesthetic technique and the aesthetic taste. On the other hand, there are common practices of equating the aesthetic curricula with the professional aesthetic courses and attempting to combine it with professional knowledge to permeate aesthetic values. Some colleges even set up the courses like the psychological counseling course, minority languages, and traditional Chinese studies. On the whole, all these courses have not undergone the instruction of the method like "why to be aesthetic, and how to be aesthetic", thus fail to achieve the goal of the aesthetic education.

\section{ANALYSIS OF IMPLIED WORRIES OF THE AESTHETIC EDUCATION IN HIGHER EDUCATION UNDER THE CONTEXT OF VALUES PLURALISM}

Facing the predicaments of college aesthetic education practice, the existing documents have already mentioned several critical factors like the curricula, faculty, administration, management and evaluation system, and investment. (Sun Rongchun 2009; Liu Guirong 2012; Qiu Di 2015) However, we cannot only discuss the superficial problems. Given the current situations of aesthetic education in today's colleges in China, this paper maintains that the central government, the school, authority of college, and the faculty contribute to the implied worries in the aesthetic education practice.

\subsection{The Bottlenecks of the Aesthetic Education Policies}

First of all, there is bottleneck of the supporting policies. Since the founding of People's Republic of China, the clear-cut expressions on aesthetic education is stated in The Constitution in 1978 and The Education Act in 1995, according to which, "students could be developed morally, intellectually, physically and etc." and "students could be developed in an all-round way: 
morally, intellectually, physically and etc." Not until the Third National Education Conference in June of 1999, the aesthetic education could be stressed as "the moral, intellectual, physical and labouring education".(Lin, Xiaoying 2019) From the "three aspects of education" (morally, intellectually and physically.) to "four aspects of education" (morally, intellectually, physically and labouring) to "five aspects of education" (morally, intellectually, physically, aesthetically and labouring), the importance of the aesthetic education has been enhanced though it faces the developmental bottlenecks.

Second, there is the bottleneck of the higher education system. The Soviet mode is copied and implemented in the education system, so talents are cultivated according to the planned economy. Facing the market economy and market-oriented choice of jobs, the narrowed professional cultivation system can hardly meet the demand of society. (Yiqiu Wang, 2019) Therefore, nearly all universities restart the aesthetic education reform which characterizes with "combination of liberal arts and science and engineering". However, in terms of system vicissitude, the effect of path dependence still works. (Yuesheng Wang, 2000) Most universities view aesthetic education as the profession, and the relative courses are taken over by the college of fine arts. The aesthetic education is still not understood beyond the discipline, or professional education.

The predicament of thinking solidification in the aesthetic education does exist. Yongnian Zheng puts forward that "disintegrated mode" and "integrated mode" in the education reform.(Yongnian, Zheng 2012:9-12) The former puts more emphasis on the precedent order to push the development of economy, society and politics, while the latter emphasizes all. The aesthetic education reform, following this thinking pattern, is left behind. (Linjie, Cheng, 2006) Both society and the individual think the aesthetic education is not that important. The aesthetic education is to reform from colleges, which will involve problems such as how to establish an ideal mechanism to enhance the quality of curricula (Linjie, Cheng 2006), to enforce the staff of aesthetic education courses to overcome the pragmatism, utilitarianism (Rongchun Sun, 2009) and technicism, and to evaluate the quantitative (Yueming Zhang, 2009), etc.

\subsection{The Spacial Limitation of Aesthetic Education Development}

Few universities have established the major of aesthetic education. The chief reason is the lacks of qualified faculty. In terms of the faculty of the aesthetic education in China, most of them are engaged in the education of fine arts, music, and movie culture and some of them are lecturers of general courses in vocational college. All of them tend to think that they are responsible for those students who are majored in arts, and they are not responsible for the aesthetic education for all registered students. What's worse, aesthetic education cannot contribute too much to the development in their field because what they "devote" does not equal to what they "gain".

Second, the aesthetic education faces the professional discrimination. Tony Becher holds that "physicists believe that they are more excellent than general scholars, historians deem that they are better than geographers, and economists look down upon the sociologists..." (Becher Tony and Paul Teroller 2015:96) Traditionally, those professions with more outcomes are confined in science and engineering, however, aesthetic professions are often in low status, the humanity and social sciences usually are even marginalized or discriminated.

Third, aesthetic education is still the nonmainstream. Most people in their minds still make light of the aesthetic education. For instance, the students majoring in other professions tend to regard it as "none of their own business" if they are involved in music, calligraphy, and film and television arts. The purpose of participating in these courses is to release pressure and to entertain or amuse themselves. Most faculties are not actively willing to take over those courses.

\subsection{The Contradiction between "Substantialization" and "Desubstantialization"}

The aesthetic education faces the theoretical controversy between the substantialization and desubstantialization. "The Spirit of Place" by Christian Norberg-Schulz thinks that "the place is a whole composed of the essence, form, texture, and colour of things."(Norberg-Schulz 2010:7) "The spirit of place" reflects that humans have to do a certain activity in a specific time and space, because they have already had the "habitus".(P. Bourdieu 1990 53) Reflecting on the aesthetic education, there are two controversial debates: one is that the aesthetic education should insist on the road of "desubstantialization", that is, "non-professional place"; the other is that the aesthetic education should adhere to the thread of "substantialization", that is, "professional place allocation".

Substantialization and desubstantialization need the corresponding allocation. The theory of "professional place allocation" believes that the aesthetic education also is supposed to have its own status like fine arts, music and other aesthetic professions-- specific curricula is to be established textbooks is being offered, a fixed teaching faculty team is to be built, and the corresponding management organizations shall be set up. The theory of "non-professional place" believes that there is no need to set up the specific major for aesthetic 
education because the essence and characteristics of the aesthetic education are similar to those of the general courses. Then what we can do to achieve the goal is to integrate the existing courses, or else the marginal benefit will be comparatively low.

What's more, the cultivation model of the aesthetic education is also faced with the dispute between the professional model and the general model. According to the Theory of Two Models of Knowledge Production by Gibbons M., the Model 1 is identified with the science, and the cognition and social norm determines whether the problems are important or not, whether the employees are qualified or not and what is "good" science; In the Model 2, however, the knowledge processing lies in the context of knowledge application.( Gibbons 2011:3-4) There are some similarities and differences between the aesthetic practice education as well as Models 1 and 2. The aesthetic education is not the professional cognitive practice, which can be supplemented with the basic aesthetic and aesthetic knowledge and grounded on the other knowledge learning; In addition, the aesthetic education should be practised in planned and organized ways and implanted into the whole process of college education. Mathieu Albert et al, who favour the Model 1 of the knowledge production, still regard the peer recognition as the important standard. (Guangcai, Yan 2018) Therefore, as to the aesthetic education, neither treating it as a general major nor breaking away from the traditional model of professional education is proper, instead, we have to explore an aesthetic education model which perfectly adapt to the current national conditions of China.

\section{HOW TO SOLVE THE PRACTICAL PROBLEMS OF THE COLLEGE AESTHETIC EDUCATION UNDER THE CONTEXT OF VALUES PLURALISM}

Under the context of values pluralism and multidimensional information transmission, aesthetic education is faced with such developmental obstacles as policies, environment, and practical operations, etc., which, however, are difficulties we have to conquer in the new era when coping with various challenges in spreading socialist core values or conducting the ideological and political work in the college. What we can do is to try our utmost to promote the aesthetic education under the context of values pluralism in the new era.

\subsection{To Reshape the Practical Awareness of the "Meg Aesthetic Education"}

Joseph E. Aoun once put forward that "learning should be built on the connected network system of various universities beyond the limitations of scale, space and time, etc." (Auen Joseph 2018:181) In light of the new situation, aesthetic education should expand in terms of the spatial and temporal perspectives. From the perspective of time, the aesthetic educations in primary schools, middle schools and colleges should be integrated into the lifelong education; From the perspective of space, aesthetic education should expand the marginal range from the confinement in the educational organizations to the family and the society, enforcing the communication and interaction; And from the perspective of methodology, new technology can be used to improve the aesthetic education. The reform of the general courses in the Harvard University is a perfect example in this regard, which prioritizes the methodological guidance in "what" and "why" and has achieved the goal of spanning from the art to the aesthetics. (Suhua, Zhu, 2016) Only when aesthetic education goes beyond the abstract "margins" such as the margins of space, temporality and thought, can it achieve its ultimate values.

\subsection{To Build up the Teaching and Research Base of the Aesthetic Education Curricula in the Educational Organizations at All Levels}

The key to aesthetic education is to set up a series of high-quality aesthetic education curricula. The majority of colleges in China, however, have to deal with the problem that there are no aesthetic education textbooks or aesthetic education curricula. In an effort to avoid the shortcomings aroused by the idea of "substantialization", it is absolutely essential to plan to set up the teaching and research base for aesthetic education curricula. As to the faculty, employing teachers from other disciplines and departments and even out of the university is acceptable. The distinctive curricula can be designed based on the characteristics of various universities. The currently popular "curriculum mapping" model from the universities in Taiwan is also a good example in this regard, which share its teaching plan and teaching process with students publicly via visual materials. (Wenna, Dong \& Jianmin, Gong, 2014) Students can select their own aesthetic education curricula according to their interests, which is of great help to achieve the supply-side reform in the aesthetic education.

\subsection{To Promote the Digitalization of the Aesthetic Education Curricula}

The mankind is on the way stepping into the era of artificial intelligence, and the traditional learning model has to undergo changes to keep up with time. The educational media we are accustomed to today such as the books, textbooks and classrooms will exist in other ways and forms in the future. The aesthetic education also has to adapt to the learning environment. Therefore, technological innovation, particular the digitalization of the aesthetic education needs to be promoted. In the field of "Ideological Policies in the Curricula", some 
innovations have been taken in some universities. Hereby, take Shanghai University for example. In its "Situation and Policy" course, the related content of "General Plan of Big Power" is included in the course, which is taught by two teachers who cooperate with other teachers from other disciplines. What's more, some other courses also have been set up in the Shanghai University such as "Creative China" and "Making Business in a Lifetime", which has been proven effective. (Lianzhi Jiao, 2019) The digitalization of the aesthetic education does not merely refer to utilizing new creative platforms like the internet. More importantly, it calls upon the efforts from students, teachers and other subjects who can participate in. Ultimately, the aesthetic education can be dramatically enhanced to a higher level through the digitalization and intellectualization

\section{CONCLUSION}

Aesthetic education in universities has been attached great importance by the central government, but under the context of value pluralism in the new era, the practice of aesthetic education in universities is facing internal and external crisis. On the one hand, this crisis is embodied by the shift of aesthetic education from the academic domain to practicality, that is, from Western enlightenment concept under the context of West philosophical aesthetics to the systematic practice acting on daily life of citizens. On the other hand, the predicaments are reflected by the poor adjustment to the reform of aesthetic education, the dispersion and fragmentization of the curriculum system, and the confinement of aesthetic capacity into professional cognitive practice in the new era. Exploring the reasons, the study believes that the government, universities, and faculty are three main contributors that cause the current problems of aesthetic education practice in higher education institutes. The specific manifestations are the bottleneck of aesthetic education policies, the spacial limitation of aesthetic education development, and the contradiction between "substantialization" and "desubstantialization". To promote aesthetic education, it is recommended that (1) the practical awareness of the "meg -aesthetic education" in the ideological context should be reshaped under the context of value pluralism in the new era; (2) the teaching and research base for aesthetic education should be established in higher education institutes; (3) the digitalization of aesthetic education curricula should be actively promoted.

\section{ACKNOWLEDGMENTS}

This study was funded by Action Plan for Sports and Aesthetic Education Infiltration of the Ministry of Education of China (Project No.:201952) and Research on Professional Challenges and Coping Strategies of Educational Theorists under the Context of Cooperation between Universities and Primary and Middle Schools (Project No.:2020W182)

\section{REFERENCES}

[1] Tang, Yingjie. 2002. A Survey to the Concept of Aesthetic Education. Journal of South-West Normal University 28(2): 70-76. DOI: 10.13718/j. cnki. xdsk. 2002. 02. 016

[2] Sun, Rongchun. 2009. Analysis of Current Problems of the Aesthetic Education in Higher Education. Hei Longjiang Higher Education Research (10): 155-157. DOI: 10.3969/j. issn. 1003-2614. 2009. 10. 051

[3] Sun, Rongchun Liu, Guirong, Wang Dongxing. 2012. Research on the Management and Modernity of the Aesthetic and Aesthetic Education in the Higher Education. Journal of Hebei University (Philosophical and Social Science) (1): 13-16. DOI: 10. 3969/j. issn. 1000-6378. 2012. 01.004

[4] Qiu, Di. 2015. The Probe into the predicament and countermeasure the Aesthetic Education in the Universities Faces. The Education Probe (6): 87-90. DOI: CNKI: SUN: SEEK. 0. 2015-06-023

[5] Lin, Xiaoying. 2019.Twenty Years of Education Quality: Dominance and Reflection of Competitive Expressionism. The Education Review of Beijing University 17 (4): 77.

[6] Wang, Yiqiu. 2019. Quality Education: Retrospect and Reflection. The Education Review of Beijing University 17 (4): 66.

[7] Wang, Yuesheng. 2000. Nothing Can be Accomplished without Norms of Standards: Free Talk about New-institutional Economics. Beijing: Sanlian Bookstore.

[8] Zheng, Yongnian. Three Steps of Chinese Economy. Beijing: Oriental Publishing House.

[9] Cheng, Linjie. 2006. The Current Situation and Way Out of the Aesthetic Education Practice in the Higher Education. Adult Education in China (8): 68-69. DOI: 10.3969/j.issn.1004-6577. 2006. 08. 043

[10] Sun, Rongchun. 2009. Analysis of the Current Problems of the Aesthetic Education in the Higher Education. The Higher Education Research in Hei Longjiang Province (10): 155-157. DOI: 10. 3969/j. issn.1003-2614. 2009. 10. 051

[11] Chen, Hong. 2007. Analysis of the Problems and Countermeasure of the Aesthetic Education in the Financial and Economics Universities. Education 
and Vocation (35): 103-105. DOI: 10. 3969/j. issn. 1004-3985. 2007. 35. 046

[12] Zhang, Yueming. 2009.On the Attenuation and Consolidation of the Aesthetic Education in the Higher Education of China. The Contemporary Science of Education (9): 60-62. DOI: CNKI: SUN: SDJK. 0. 2009-09-019

[13] Becher, Tony. Paul, Teroller. 2015. Academic Tribe and Its Territory: Knowledge Explore and Disciplinary Culture. Beijing: Beijing University Press.

[14] Norberg-Schulz. 2010. Place Spirit: Towards the Architectural Phenomenology. Wuhan: Huazhong University of Science and Technology Press.

[15] Bourdieu, P. 1990. The Logic of Practice. Cambridge: Polity Press.

[16] Gibbons. 2011.The New Model of Knowledge Production: Dynamics of the Contemporary Social Science and Research. Beijing: Beijing University Press.

[17] Yan, Guangcai. 2018. Academic Science and Transferring Logic of Industrial Techniques: The American Experiences. The Education Review of Beijing University 16 (3): 97. DOI: CNKI: SUN: BJPL. 0. 2018-03-008

[18] Auen, Joseph. 2018. The Future of Education: Educational Reform in the AI Era. Beijing: China Machine Press.

[19] Zhu, Suhua. 2016. The Enlightenment of the General Courses in Harvard University on the Aesthetic Education in China. The Aesthetic Variety 32 (S1): 321-322. DOI: 10.3969/j. issn. 1003-9104. 2016. z1. 113

[20] Dong, Wenna \& Gong Jianmin. 2014. What is Curricula Map? Research on the Educational Development 34 (17): 56-64. DOI: 10.14121/j. cnki.1008-3855. 2014. 17. 028.

[21] Jiao, Lianzhi. 2019. From "Disciplinary Morals" to "Ideological Thoughts in the Courses": The Innovation of Aesthetic Education in the Higher Education under the Context of President Xi's Thoughts. Journal of Jimei University 20 (1): 1-6. DOI: CNKI: SUN: JMDX. 0. 2019-01-001 